\title{
AS LEITURAS ASPECTUAIS DA FORMA DO PROGRESSIVO DO PB
}

Teresa Cristina Wachowicz *

\section{Introdução}

forma do progressivo (estar + verbo em -ndo) tem sido largamente
usada pelos falantes de PB. Com relação especificamente às leituras
aspectuais quantitativas (Castilho; Moraes de Castilho, 1994), o progressivo exibe variação de leitura aspectual - entre os valores episódico, iterativo e habitual. Em detrimento dos valores aspectuais qualitativos, usualmente conhecidos por perfectivo e imperfectivo, os valores quantitativos podem ser assim conceituados: o valor episódico refere a um evento só, relativo a um único intervalo de tempo; o valor iterativo refere a vários eventos determinados, com respectivos intervalos de tempo; e o valor habitual refere a vários e indeterminados eventos, também com seus correspondentes intervalos de tempo.

A primeira hipótese teórica é que essas leituras dependem de um tratamento composicional de aspecto, nos termos de Verkuyl (1993; 1999). Para a checagem dessas interpretações, foram realizados testes em falantes naturais de português. A segunda hipótese teórica, a partir daí, é que o tratamento

\footnotetext{
* Universidade Federal do Paraná e Pós-Graduação da Universidade de São Paulo.
} 
composicional deve levar em consideração, igualmente, informações sobre as relações temáticas da sentença, nos termos de Krifka (1992). Este trabalho tem como objetivo apresentar os resultados das análises empíricas e, também, levantar as hipóteses teóricas para o tratamento formal da interpretação aspectual das sentenças no progressivo.

\section{As sentenças do Varsul}

No primeiro momento das observações empíricas, optamos por rastrear um banco de dados da fala de falantes urbanos de PB da região sul do Brasil, o Varsul, cuja sigla significa Projeto de Variação Lingüística do Sul do Brasil. Nas sentenças observadas com o progressivo, constatamos que o primeiro valor aspectual lido é o imperfectivo e isso é determinado pela marca morfológica -ndo do verbo principal. ${ }^{1}$ Os valores episódico, iterativo e habitual são dependentes de leitura composicional (natureza semântica do verbo no gerúndio, natureza semântica do argumento interno, modificações adverbiais), nos termos de Verkuyl.

Antes de examinarmos as sentenças do Varsul, faz-se necessária uma revisão de alguns conceitos trazidos da teoria de Verkuyl: a informação [ \pm ADDTO] é um traço semântico para itens verbais e, no seu valor positivo, caracteriza verbos que denotam mudança no tempo (Verkuyl, 1993, p. 16: additive to). São [+ADDTO] verbos como comer, andar, tricotar e são [-ADDTO] verbos como querer e odiar. Por outro lado, [ \pm SQA] é um traço semântico para expressões nominais e, no seu valor positivo, caracteriza NPs que denotam um indivíduo A com quantidade especificada (Verkuyl, 1993, p. 140: specified quantity of $A$ ). Assim, são [+SQA], por exemplo, nomes com cardinalidade definida ( um carro, três árvores,...), e são [-SQA], por exemplo, plurais e singulares nus, termos de massa e nomes genéricos (carros, farinha, lição,...). Verkuyl emprega esses traços na determinação dos valores aspectuais perfectivo e imperfectivo. ${ }^{2}$ Nossa idéia aqui é que esses traços também podem ser determinantes na leitura dos valores episódico e iterativo.

10 valor imperfectivo da forma do progressivo precisaria, evidentemente, ser testado. No entanto, neste primeiro momento, vamos na esteira das teorias que associam o valor imperfectivo ao progressivo, tanto para o português (Godoy, 1992; Castilho, 1967; Castilho e Moraes de Castilho, 1994) quanto para o inglês (Dowty, 1979; Vlach, 1981; Zucchi, 1998).

2 A terminologia de Verkuyl emprega os nomes terminativo $x$ durativo para os valores perfectivo $x$ imperfectivo, respectivamente. Guardados os comentários sobre opções de nomenclatura de acordo com correntes teóricas, essa correspondência pode ser feita. 
A análise nos dados do Varsul pode ser sintetizada e exemplificada da seguinte forma:

Tabela 1 - Síntese das observações realizadas no Varsul

\begin{tabular}{|c|c|c|c|}
\hline \multirow{2}{*}{ exemplos de sentenças do VARSUL } & \multirow{2}{*}{$\begin{array}{l}\text { Natureza sintático-semântica } \\
\text { dos constitumtes }\end{array}$} & \multicolumn{2}{|c|}{ valores } \\
\hline & & Episódico & $\begin{array}{l}\text { iterativo/ } \\
\text { habitual }\end{array}$ \\
\hline $\begin{array}{l}\text { Então, aqui pelo menos ela está } \\
\text { trabalhando. }\end{array}$ & Verbo intransitivo [+ADDTO] & $\mathbf{X}$ & $\mathbf{X}$ \\
\hline Ela está evoluindo. & $\begin{array}{l}\text { Verbo intransitivo } \\
\text { [-ADDTO] }\end{array}$ & $X(?)$ & \\
\hline $\begin{array}{l}\text { Só estou sentindo deus ali dentro do } \\
\text { meu coração. }\end{array}$ & $\begin{array}{c}\text { Verbo transitivo } \\
\text { [-ADDTO] mais NPintermo } \\
{[+ \text { SQA }]}\end{array}$ & $X(?)$ & \\
\hline Ela está limpando aquele parque. & $\begin{array}{l}\text { Verbo transitivo [+ADDTO] } \\
\text { mais NPinterno [+SQA] }\end{array}$ & $\mathrm{X}$ & $\mathbf{X}$ \\
\hline $\begin{array}{l}\text { Era dez e pouco, onze da manhā, } \\
\text { estava dormindo tranquïilo. }\end{array}$ & $\begin{array}{l}\text { Qualquer estnutura argumental } \\
\text { com advérbios momentâneos }\end{array}$ & $\mathrm{X}$ & \\
\hline $\begin{array}{l}\text { Você estava panfleteando na cidade } \\
\text { industrial }\end{array}$ & Verbo intransitivo [+ADDTO] & & $\mathbf{X}$ \\
\hline O pessoal só estava querendo esgoto. & $\begin{array}{l}\text { Verbo transitivo } \\
\text { [-ADDTO] mais NPinterno [- } \\
\text { SQA] }\end{array}$ & $X(?)$ & $X(?)$ \\
\hline $\begin{array}{l}\text { Depois do trecho do trem, agora } \\
\text { estão plantando árvores. }\end{array}$ & $\begin{array}{l}\text { Verbo transitivo [+ADDTO }] \\
\text { mais NPintemo [-SQA] }\end{array}$ & $\mathrm{X}$ & $\mathbf{X}$ \\
\hline $\begin{array}{l}\text { Acho que de minuto em minuto está } \\
\text { passando ônibus }\end{array}$ & $\begin{array}{l}\text { Qualquer estrutura argumental } \\
\text { com advérbios frequienciais }\end{array}$ & & $\mathrm{X}$ \\
\hline
\end{tabular}

De acordo com a tabela acima, há duas observações centrais que necessitam ser explicadas. A primeira delas diz respeito às sentenças cujos verbos no gerúndio têm valor -ADDTO. Esses verbos parecem deslocar a interpretação aspectual quantitativa para uma leitura que poderia ser interpretada como um episódico estendido ou então um habitual homogêneo (daí os sinais de interrogação acompanhando as referidas interpretações). É como se as sentenças com 
verbos -ADDTO, conhecidas na literatura da aktionsarten como "estativas", não tivessem definição temporal, denotando eventos, ou estados de coisas, que permanecem na linha temporal, sobrepondo-se a outros eventos, com leitura temporal. Uma alternativa para essa constatação empírica, seguindo a nomenclatura de valores aspectuais, é denominar essa leitura de "permansiva" (Mendes, 1999). As sentenças com verbos +ADDTO têm interpretações quantitativas mais tranquiilas: os valores episódico, iterativo/ habitual são mais bem aceitos.

A segunda observação referente à tabela diz respeito à freqüente ambigüidade verificada em sentenças sem modificação adverbial. Quer dizer, dentro de determinados contextos, a maioria das sentenças são ambíguas. Tomamos o aspecto como uma entidade semântica cuja leitura tem vários níveis hierarquizados: o nível da estrutura argumental, o nível da sentença com modificações adverbiais e o nível do contexto. Nesse sentido, o contexto atua como definidor de leituras intrinsecamente presentes na estrutura sentencial, e não como operação pragmática que impõe valores construídos contextualmente. Em outros termos, a estrutura sentencial é naturalmente ambígua; e o contexto tem o papel de "escolher" uma das possíveis leituras da estrutura.

\section{O teste de interpretação aspectual}

Dada a variação de leituras verificadas nos dados do Varsul, julgamos ser necessária a realização de uma bateria de testes para a checagem dessas "intuições", ampliando, inclusive, as naturezas sentenciais que seriam pertinentes às leituras aspectuais. Nesse sentido, algumas opções relativas ao teste precisam ser justificadas:

1) O papel do argumento externo foi desconsiderado. Sob o ponto de vista teórico, justificamos esta opção por três motivos: (i) pela assimetria argumental defendida por Kratzer (2000); (ii) pela assimetria interpretativa defendida por Verkuyl (1999), segundo o qual a leitura aspectual está centralizada na estrutura do VP, tendo o sujeito apenas papel determinante nos "modos de interpretação" coletivo $x$ distributivo; e (iii) pelas diferentes leituras pluracionais defendidas por Lasersohn (1995).

2) Optamos por testar sentenças com verbos [ \pm ADDTO] intransitivos e transitivos. Se a perspectiva é composicional, há a necessidade de se checar o papel do item verbal isoladamente.

3) Os NPs em posição de argumento interno são ou [+SQA] (o indefinido singular e o numeral nu) ou [-SQA] (o bare plural e o bare singular), conforme 
nomenclatura de Muller (2001). Ainda foram testados NPs quantificados distributivamente com cada, conforme Negrão (2001), segundo a qual essa quantificação estaria relacionada à pluralidade de eventos.

4) Quanto às modificações adverbiais, a opção foi modificar as combinações possíveis entre verbos e NPs com os seguintes advérbios: (i) com advérbios momentâneos (hoje às 20 horas) e habituais (sempre), (ii) com advérbio aspectualizador episódico (de uma vez só) e iterativo (algumas vezes), conforme sistematização de Ilari (1990), (iii) com advérbio frequiencial (frequientemente) e (iv) com advérbios durativos com por- (por um dia, por uma semana, por um ano), para checar, conforme Van Geenhoven (2001), segundo a qual os advérbios for- em inglês selecionariam VPs pluracionais (ou, em nossos termos, iterativos). Nossa intenção é checar essa tese linguíística para o português com advérbios por-.

A partir dessas opções, a síntese das estruturas sentenciais está sistematizada na tabela abaixo:

Tabela 2 - Sistematização das sentenças no progressivo para os testes

\begin{tabular}{|c|c|c|c|c|}
\hline $\begin{array}{c}\text { O argumento } \\
\text { externo } \\
\text { (singular } x \text { phural) }\end{array}$ & $\begin{array}{l}\text { O verbo estar } \\
\text { (singular } x \\
\text { plural) }\end{array}$ & $\begin{array}{l}O \text { verbo no } \\
\text { gerúndio } \\
\text { (intrans itivo } x \\
\text { transitivo) }\end{array}$ & $\begin{array}{l}O \text { argumento intemo } \\
\text { (individuo singular } x \\
\text { plurais } x \text { genéricos } x \\
\text { quantificados) }\end{array}$ & $\begin{array}{l}\text { A modificação } \\
\text { adverbial } \\
\text { (adv. pontuais } x \\
\text { adv. iterativos } x \\
\text { advérbios por-) }\end{array}$ \\
\hline \multirow{19}{*}{$\begin{array}{c}\text { Joāo } \\
\text { A professora }\end{array}$} & \multirow{17}{*}{ está } & vivendo & & \multirow{24}{*}{$\begin{array}{l}\text { de uma vez só } \\
\text { algumas vezes } \\
\text { frequitentemente }\end{array}$} \\
\hline & & dormindo & & \\
\hline & & trabalhando & & \\
\hline & & dirigindo & & \\
\hline & & \multirow{5}{*}{ possuindo } & uma propriedade & \\
\hline & & & três propriedades & \\
\hline & & & propriedades & \\
\hline & & & propriedade & \\
\hline & & & cada propriedade & \\
\hline & & \multirow{5}{*}{ sabendo } & uma lição & \\
\hline & & & duas liçōes & \\
\hline & & & liçöes & \\
\hline & & & liçāo & \\
\hline & & & cada lição & \\
\hline & & \multirow{5}{*}{ sentindo } & uma dor & \\
\hline & & & quatro dores & \\
\hline & & & dores & \\
\hline & \multirow{7}{*}{$\begin{array}{l}\text { estão } \\
\text { estão }\end{array}$} & & dor & \\
\hline & & & cada dor & \\
\hline \multirow{5}{*}{$\begin{array}{l}\text { As crianças } \\
\text { As fábricas }\end{array}$} & & \multirow{5}{*}{ vivendo } & uma experiência & \\
\hline & & & duas experiências & \\
\hline & & & experî̀ncias & \\
\hline & & & experiência & \\
\hline & & & cada experiência & \\
\hline
\end{tabular}




\begin{tabular}{|c|c|c|c|c|}
\hline & & \multirow{6}{*}{ vendendo } & um sonho & \\
\hline & & & dois sonhos & \\
\hline & & & sonhos & \\
\hline & & & o sonho & \\
\hline & & & sonho & \\
\hline & & & cada sonho & \\
\hline \multirow{5}{*}{$\begin{array}{c}\text { Joāo } \\
\text { A professora }\end{array}$} & \multirow{6}{*}{$\begin{array}{l}\text { está } \\
\text { está }\end{array}$} & \multirow{5}{*}{ plantando } & uma árvore & \multirow{4}{*}{$\begin{array}{c}\text { hoje às } 20 \text { horas } \\
\text { sempre }\end{array}$} \\
\hline & & & três árvores & \\
\hline & & & árvores & \\
\hline & & & árvore & \\
\hline & & & cada árvore & \multirow{6}{*}{$\begin{array}{l}\text { de uma vez só } \\
\text { algumas vezes } \\
\text { freqüentemente } \\
\text { por uma hora } \\
\text { por uma semana } \\
\text { por um ano }\end{array}$} \\
\hline \multirow{5}{*}{$\begin{array}{l}\text { As crianças } \\
\text { As fábricas }\end{array}$} & & \multirow{5}{*}{ dirigindo } & um carro & \\
\hline & \multirow{4}{*}{$\begin{array}{l}\text { estão } \\
\text { estão }\end{array}$} & & dez carros & \\
\hline & & & carros & \\
\hline & & & carro & \\
\hline & & & cada carro & \\
\hline
\end{tabular}

Os informantes foram 5 rapazes e 5 moças - estudantes universitários -, com faixa etária e grau de escolaridade semelhantes. Poucas orientações iniciais foram dadas aos informantes, de modo que cada um deles só precisaria marcar um $X$ na possibilidade de a sentença ser ruim ou boa, e um $X$ na leitura aspectual episódica, iterativa/habitual ou ambas, ficando a possibilidade contextual por conta dos informantes. Em média, eles levaram aproximadamente 40 minutos para completar cada teste.

Como resultado da segunda etapa de observaçōes empíricas - a dos testes -, podemos expor os resultados, que aqui não têm o menor critério estatístico, nem tampouco a menor tentativa de síntese, pois, para este momento, não houve tempo para realizar a computação numérica e a organização das conclusões. Desta forma, podemos sistematizar seis comentários sobre os resultados:

1) As sentenças com verbos intransitivos, sem modificação adverbial, foram aceitas em sua maioria com leitura aspectual ambígua (23/39), mas a sentença com o verbo dormir (João está dormindo) tem também leitura episódica (4/ 10), enquanto que com verbo trabalhar (João está trabalhando) tem também leitura iterativa/habitual (5/10).

2) As sentenças com verbos intransitivos com modificações adverbiais mostram que os advérbios resolvem as leituras ambíguas das sentenças. $\mathrm{O}$ advérbio momentâneo hoje às 20 horas e o advérbio aspectualizador de uma vez só são pouco aceitos com os verbos viver e dirigir: $21 / 40$ das sentenças com esses advérbios foram consideradas ruins (??João está vivendo hoje às 20 horas; ??João está dirigindo carros de uma só vez). Os advérbios sempre, 
freqüentemente e algumas vezes foram mais bem aceitos (99/120), com predominância da leitura iterativa/habitual (84/120). O verbo viver não foi bem aceito aqui: 23/30 das sentenças modificadas foram consideradas ruins (??João está vivendo algumas vezes). Com relação aos advérbios iniciados por por-, observa-se que, quando referem a um intervalo pequeno de tempo (uma hora ou uma semana), a leitura é episódica (34/80) ou ambígua (22/80) (João está trabalhando por uma hora); mas, quando referem a um intervalo de tempo mais extenso (um ano), a leitura fica iterativa/habitual (14/40) ou ambígua (13/40) (João está trabalhando por um ano).

3) As sentenças com verbos transitivos sem modificação adverbial têm a leitura aspectual dependente também da natureza semântica dos NPs em posição de argumento interno. As sentenças com verbos [-ADDTO] e complementos tanto +SQA quanto -SQA, como possuir, tendem à interpretação episódica (João está possuindo quatro propriedades/ João está sabendo liçōes), sendo pertinente a observação aqui de que a melhor terminologia para essa leitura seria "permansiva". Com verbos [+ADDTO], como plantar, a leitura tende a ser episódica quando o argumento interno for [+SQA] (João está plantando três árvores): 20/ 40 são lidas como episódicas e $15 / 40$ como ambíguas. Por outro lado, quando o argumento interno for [-SQA] (João está plantando árvore), a leitura é ambígua: 13/35 são lidas como iterativas e 18/35 como ambíguas.

4) As sentenças com verbos transitivos com modificações adverbiais, com NPs [ $\pm \mathrm{SQA}$ ], parecem acompanhar a tendência verificada para os verbos intransitivos: os advérbios hoje à 20 horas e o de uma vez só tendem a leitura para o valor episódico, enquanto que os advérbios sempre, algumas vezes $\mathrm{e}$ freqüentemente tendem a leitura para o valor iterativo/habitual. Quanto aos advérbios por uma hora, por uma semana e por um ano, há a tendência de os dois primeiros tenderem à leitura episódica e o terceiro à leitura iterativa/habitual.

Numa tentativa de resumo da primeira observação sobre o resultado dos testes, em termos bastante gerais, podemos dizer que: 1) os verbos [-ADDTO] tanto intransitivos quanto transitivos tendem à leitura "permansiva"; 2) os verbos [+ADDTO] intrasitivos tendem à ambigüidade; 3) a natureza [ \pm SQA] do NP argumento interno é determinante no valor aspectual da sentença: NPs [+SQA] tendem à leitura episódica, enquanto que os [-SQA] tendem à leitura ambigüidade episódico $x$ iterativo/habitual; 4) os advérbios momentâneos, aspectualizadores e frequienciais tendem a resolver a leitura aspectual das sentenças.

Há ainda uma última observação que cabe fazer aqui. A diferença de leitura entre as sentenças João está sentindo quatro dores e João está dirigindo dez carros parece necessitar de algo a mais do que a distinção [ \pm ADDTO] 
para os verbos. A primeira sentença pode ser ambígua, mas a segunda é claramente iterativa/habitual, pois há restrições contextuais muito fortes para se admitir que João dirija dez carros de uma só vez. Nesta segunda sentença, há uma relação de unicidade entre evento e indivíduo denotado pelo argumento interno: para cada evento de dirigir só pode haver um carro, e vice-versa. Ao passo que, para a primeira sentença, não precisa haver necessariamente essa unicidade entre evento e indivíduo argumento interno. É uma propriedade sobre a relação temática de paciente que explica a restrição de leitura aspectual aqui. Logo, para a visão composicional de leitura aspectual que queremos defender aqui, além das informações sobre os constituintes sentenciais, há a necessidade de se ter informações sobre as relações entre esses constituintes.

\section{Conclusão: hipóteses teóricas}

Se a leitura aspectual das sentenças no progressivo depende, inicialmente, da natureza semântica dos constituintes sentenciais e do tipo de combinação entre eles, ela só pode ter natureza composicional. Quer dizer, não é questão de a leitura aspectual poder sofrer "coerção de tipo" no nível de leitura contextual, como propõe Swart (1998), ou de ela ser resolvida por relações entre ponto de referência e ponto de evento, considerando-se apenas a leitura do item lexical dos verbos, como propõe Johnson (1981). A leitura aspectual depende, na verdade, de vários níveis - desde o lingüístico-estrutural até o contextual. Com relação ao nível lingüístico, da sentença, se ela é composicional, Verkuyl (1993; 1999) dá base tanto empírica quanto teórica ao nosso trabalho. A sua estrutura sintática, aos moldes da gramática categorial, leva em conta traços semânticos relevantes para o aspecto: é o caso dos traços \pm ADDTO e \pm SQA dos constituintes verbais e nominais, respectivamente.

Sob o ponto de vista semântico, ainda há questões interessantes:

1) Se os testes revelaram um comportamento heterogêneo das sentenças, há a hipótese de que não é só a partir de traços $\pm \mathrm{ADDTO}$ e $\pm \mathrm{SQA}$ que $o$ valor aspectual da estrutura argumental se constrói. Possivelmente, precisamos justificar as variações a partir de propriedades sobre relações temáticas existentes entre as sentenças. O trabalho de Krifka (1992) tem respostas para isso.

2) Se formos pensar ainda em modelo de interpretação e numa conceituação de aspecto como sendo a qualidade interna do tempo, como ficariam as informações sobre os intervalos de tempo conseqüentes da interação entre as informações dos constituintes sentenciais e informações das relações 
temáticas? Como uma semântica de intervalos de tempo formalizaria a leitura iterativa em oposição à episódica, além da formalização do aspecto perfectivo $x$ imperfectivo? Numa perspectiva modelo-teorética, Link (1997), com sua proposta da álgebra de eventos, teria respostas em termos bastante genéricos, mas como formalizar as representações específicas das sentenças no progressivo?

\section{RESUMO}

A partir de observaçōes em sentenças do Projeto Varsul e de testes de interpretação aspectual, constatou-se que a forma do progressivo em PB (estar + -ndo), além de ter valor aspectual imperfectivo, sob o critério qualitativo, exibe variação de leitura episódica, iterativa e habitual, sob o enfoque quantitativo. A hipótese teórica central é que essas leituras são de natureza composicional.

Palavras-chave: progressivo, aspecto, composicionalidade.

\section{ABSTRACT}

Observations on Varsul Project database and aspectual reading tests on BP speakers showed us that the progressive form in BP (estar verb + -ndo) has different values: the imperfective reading, under the qualitative criterion, and the episodic, iterative or habitual readings, under the quantitative criterion. The central theoretical hypothesis is that these readings have a composicional nature.

Key-words: progressive, aspect, composicionality.

\section{REFERÊNCIAS}

CASTILHO, A. T. de; CASTILHO, C. M. M. de. O aspecto verbal no português falado. In: SEMINÁRIO DO PROJETO DE GRAMÁTICA DO PORTUGUÊS FALADO, 8., 1994, Campos do Jordão. Mimeog.

DOWTY, D. Towards a semantic analysis of verb aspect and English imperfective progressive. Linguistics and Philosophy, n. 1, p. 45-77,1977. 
WACHOWICZ, T. C. As leituras aspectuais da forma...

GODOY, E. Aspectos do aspecto. Campinas, 1992. Tese (Doutorado) - Universidade de Campinas.

ILARI, R. et al. Considerações sobre a posição dos advérbios. In: CASTILHO, A. (Org.). Gramática do português falado. Campinas: Ed. Unicamp, 1990. v. 1: A ordem.

JOHNSON, M. A unified theory of tense and aspect. In: TEDESCHI, P.; ZAENEN, A. Syntax and Semantics. New York: Academic Press, 1981. p. 145-175.

KRATZER, A. Verb meaning. In: The event argument, 2000. Mimeog.

KRIFKA, M. Thematic relations as links between nominal reference and temporal constitution. In: SAG, I. A.; SZABOLCSI, A. (Ed.). Lexical matters. CSLI lecture notes, n. $24,1992$.

\section{Publications, 1997.}

LASERSOHN, P. (1995). Plurality, conjunction and events. Stanford: Kluwer Academic Publishers, 1992.

LINK, G. Algebraic semantics of event structures. Algebraic semantics in language and philosophy. CSLI, n. 74, 1997.

MENDES, R. B. A gramaticalização de estar + gerúndio no português falado. Campinas, 1999. Dissertação (Mestrado) - Universidade de Campinas.

MULLER, A. L. Bare nouns and the mapping parameter in brazilian portuguese. Trabalho apresentado no II Workshop "A semântica do português do Brasil", USP, ago. 2001.

NEGRÃO, E. V. Distributividade em PB e a exigência de quantificą̧ão sobre eventos. Seminários de Teoria Gramatical. São Paulo: Faculdade de Filosofia, Letras e Ciências Humanas/USP, 2001.

SWART, H. de. Aspect shift and coercion. Natural language and linguistic theory, v. 16, n. 2, p. 347- 385, 1998.

VERKYUL, H. J. A theory of aspectuality. Cambridge: University Press, 1993. Aspectual issues. Studies on time and quantity. CSLI Publications, n. 98, 1999.

VLACH, F. The semantics of progressive. In: TEDESCHI, P. J.; ZAENSN, A. (Ed.). Syntax and Semantics, v. 14, p. 271-292, 1981.

ZUCCHI, S. Aspect shift. In: ROTHSTEIN, S. (Ed.). Events and grammar. Dordrecht: Kluwer, 1998. 